junction with the recent meeting of the International Federation of Documentation, will remain open to the public until October 31 .

\section{History of Luchon}

IN his inaugural dissertation on Luchon (Thèse de Paris, 1938, No. 497), Dr. P. J. M. J. Molinéry gives an interesting historical account of this celebrated health resort situated in the heart of the central Pyrenees. $\mathrm{H}_{\Theta}$ describes three distinct stages in its development, namely, the Gallo-Roman epoch, the eighteenth and nineteenth centuries and modern times. In antiquity, Luchon enjoyed a high reputation owing to the Aquæ Onesiæ, which were recommended by Oribasius and Antyllus among others for nervous and gastric disorders, skin diseases and rheumatism. Then followed a period of more than a thousand years when Luchon fell into entire oblivion. In the eighteenth and nineteenth centuries it recovered something of its former splendour. Fresh bathing establishments were built over the Roman ruins and new springs were discovered. During this period, Luchon was specially recommended for the treatment of skin diseases, rheumatism, menstrual disorders, scrofula and syphilis. In the twentieth century it became not only one of the most important of the Pyrenees sulphur stations but also one of the most radioactive centres in Europe. The diseases treated at Luchon at the present time are mainly disorders of the respiratory tract, deafness of nasal origin, rheumatism, skin diseases and secondary and tertiary syphilis.

\section{Annual Report of the Ministry of Health}

THE principal vital statistics and the health services for England and Wales in 1937 are surveyed in the recently issued nineteenth annual report of the Ministry of Health, 1937-38 (London: H.M. Stationery Office. 5s. net). The estimated mid-year population was $41,031,000$, the live births were $14 \cdot 9$, and the deaths $9 \cdot 3$, per 1,000 population. Maternal mortality in 1937 was at the record low level of $3 \cdot 11$ per 1,000 births, and great efforts are being made to reduce still further this distressing cause of death. The infant mortality rate was 58 per 1,000 live births, the lowest on record with one exception (1935). The death rate from all forms of tuberculosis was 657 per million population, and the various measures and schemes for the reduction of tuberculosis mortality are outlined. Only four cases of smallpox were notified during the year, but 55,896 cases of pneumonia were notified, compared with 46,167 cases the previous year. The increase appears to be attributable in part to an outbreak of influenza in the earlier part of the year. The notified cases of diphtheria were also more numerous than in 1936, but scarlet fever incidence was lower. Cancer deaths numbered 66,965 , remaining much the same as in the previous two or three years. Much is said on housing and slum clearance, and 337,616 houses of a rateable value not exceeding $£ 78$ were completed during the year. The Ministry of Health Vote for 1937-38 amounted to the net sum of just over twenty-two million pounds.

\section{Liverpool Naturalists' Field Club}

Tre seventy-seventh Annual Proceedings of the Liverpool Naturalists' Field Club for the year 1937, recently issued, contain a comprehensive summary of the year's fauna and flora in the Merseyside and Deeside areas, in addition to Mrs. R. Laverock's presidential address on "Defences and Adaptations in Plants", and résumés of the general field meetings of the year at local places of interest. The botanical records, compiled by Mr. J. D. Massey, include a number of new district records. Insect records are summarized by Mrs. Makinson, the entomologica] referee. A comprehensive month by month summary of the bird records by Mr. Eric Hardy, the ornithological referee, includes the occurrence of greenshanks, ruffs, peregrines, curlew-sandpipers, green sandpipers, the sabine's gull and little gull in the area, the increase of nesting tufted ducks, teal, redshanks, and lesser black-backed gulls, the results of surveys of magpie, coot and red-backed shrike distribution carried out for the British Trust for Ornithology, and the nestcounts at the rookeries and heronries in the district. The Society is increasing the number of prizes offered for natural history work during the year to nine.

Research at King's College, Newcastle-upon-Tyne

FollowING on the reconstitution of the University of Durham, involving, as it did, the amalgamation in King's College of the former Armstrong College and the College of Medicine, the Standing Committee for Research established in 1923 in Armstrong College with an endowment of $£ 12,000$ has been reconstructed so as to include representatives from the Medical School. The Standing Committee's report for 193637, which gives particulars of twenty-four grants, amounting in the aggregate to $£ 900$, made during that session, announces the provision of a senior research fellowship tenable during 1938-39, to enable a member of the staff of King's College to undertake research upon a specific problem necessitating complete absence from teaching duties. The report shows no signs of diminution of research activities in any department of the College. Conspicuous among them have been the Siwa Oasis Expedition, in respect of which Mr. J. Omer-Cooper received a grant from the Committee, Mr. R. F. Peel's investigations of sand formations and the movement of dunes in the Libyan desert, and botanical and zoological researches in the Hebrides.

\section{Scientific Work in Moravia}

BRNo (Brünn), the capital of Moravia and the home of Mendel, has good facilities for scientific research. Besides the Masaryk University, founded in 1919, there are the Czech and German colleges of technology and also medical, veterinary and agricultural schools. All these are staffed with specialists engaged in directing research as well as in teaching. The results of their investigations are mostly published in the Spisy vydávané $P^{`}$ irodovédeckou Fakultou Masarykovy University (Publications of the Faculty of Sciences of the Masaryk University), edited by Prof. A. Simek, or in the periodical Bulletins of the various colleges and in the Proceedings of the Moravian 
Scientific Society. In this way all branches of the natural sciences in Moravia are represented in publications which reflect the high standard of work performed by contemporary Moravian men of science, including discoveries in archæology, geology, ecology and biology in addition to meritorious physicochemical researches.

\section{Mercury Poisoning}

A REview of present knowledge as to the liability of users of mercury to contract mercury poisoning by continued exposure to mercury vapour or to solutions of mercury compounds of small concentration has recently been issued (Rev. Sci. Inst., Aug.). Although there are great differences in the sensitivity to poisoning amongst individuals, it seems certain that prolonged exposure to an atmosphere containing one quarter of a milligram of mercury vapour per cubic metre of air is dangerous. As the saturation vapour pressure of mercury at $18^{\circ} \mathrm{C}$. is such that there is more than $10 \mathrm{mgm}$. of mercury in a cubic metre, it is evident that exposure of considerable surfaces of mercury to air at ordinary temperatures should be avoided. Good ventilation is the best precaution where exposed surfaces are unavoidable, and this failing, gas masks containing carbon-iodine absorber should be used. Rubber gloves should be worn to prevent contact with mercury or mercury solutions.

\section{Optical Utilities}

Messrs. W. Watson and Sons, Ltd., 313 High Holborn, London, W.C.1, have issued a booklet entitled "Optical Utilities", containing a catalogue of small optical instruments for aiding vision. These include magnifiers mounted as spectacles, the "Speera" for dissecting or viewing minute objects, and the "Spectopera" for viewing distant scenes, a magnifying glass with electric bulb in the handle for examining maps, prints, etc., a "Strip" magnifier for reading small print, a pocket lens compass, the needle of which is mounted between two lenses so that it can be used as a pocket magnifier, and other useful devices.

\section{Noise Insulation}

THE valuable summary of the best methods of reducing noise which Dr. G. W. C. Kaye, of the National Physical Laboratory, communicated to the Journal of Scientific Instruments in June has now been issued by the Institute of Physics as a separate publication, and should be in the hands of all designers of structures in which noise is to be diminished as much as possible. The loudest of the offending noises should first be reduced at least to the average level of the others, either by reducing it at its source or by providing fewer facilities for its propagation. Against direct transmission through the air the remedy is to enclose the source or hearer in a sound-proof building, which may require its doors, windows, walls and floors to be heavy or double with intervening air gaps, and to have its walls and ceilings lined with sound absorbing materials. Metal piping should have short lengths replaced by rubber or other less efficient transmitting material, and be supported by insulated clips.

\section{National Research Council of Japan}

THE report of the National Research Council of Japan for the year April 1936-March 1937, which has recently been published, contains a list of serial publications issued during the year, with details of the general meeting, divisional meetings and committee meetings, as well as of the international scientific meetings at which the Council was represented. In addition to the Divisions of Astronomy, Geophysics, Chemistry, Physics, Geology and Geography, Biology and Agriculture, Medical Sciences, Engineering and Mathematics, a Committee of Pacific Investigation has held five meetings and a National Committee on Radio Research ten meetings dealing with the transmission of short waves, measurements of radio waves during the total solar eclipse on June 19, 1936, studies of the ionosphere, etc. The report also gives the personnel of the various divisions and committees and a full list of serial publications received from abroad.

\section{Political and Economic Planning}

A BRoADshemt recently issued by $\mathbf{P}$ E P (Politica and Economic Planning) summarizes the progress oe $\mathrm{P} \mathrm{EP}$ in 1936-38. In the last two years the volum of published P E P work has approximately doubled, five full reports covering electricity supply, international trade, social services, health services and the Press having appeared within sixteen months, besides more than thirty regular numbers of Planning. This result has been attained by a small voluntary body with a budget of less than $£ 10,000$ a year and a paid staff of less than a dozen persons. This in itself is a striking indication of the opportunities which exist for organized thought about the future, and the most significant feature about the work of P E P is probably the extent of the opportunities it has opened up. The results already achieved suggest that by bringing to bear on public problems even a small proportion of the available intelligence and energy, it should be possible to prevent serious national and international difficulties from arising. The broadsheet gives a complete list of reports already issued as well as of the planning broadsheets, and indicates the position of the studies of regional development and industrial location, on the gas industry, on partners in industry and of the inquiry into population policies which have been initiated by $\mathrm{P} E \mathrm{P}$ and on which reports are later to appear.

\section{Science for the People}

ADVANCE reports promise that science will be well shown at the great 1939 exhibitions in Americathe Golden Gate International Exposition in San Francisco and the New York World's Fair (Science Service, Washington, D.C.). Synthetic foods will be manufactured on the spot, and laboratory rats will be fed upon the foods, and have to stand a comparative test against normally fed individuals. A complete 'chemical' garden growing indoors, without sunlight and without soil, will illustrate the production of maize, peas, melons, squash, spinach and lettuce by chemical means and ordinary incandescent light. ing. Electrical apparatus, television, sound amplifying 